\title{
Effects of Different Solvents on Co-gasification of Can Lignite with Sorghum Biomass
}

\author{
Acelya Secer \\ Department of Chemistry, Cukurova University \\ 01130, Adana, Turkey \\ ORCID: 0000-0002-5967-8700 \\ E-mail: acsecer@cu.edu.tr
}

\begin{abstract}
In this study, a mixture of sorghum biomass and Çan lignite, containing 25\% sorghum, was gasified at operating temperatures of $700^{\circ} \mathrm{C}$ and $900^{\circ} \mathrm{C}$ using tetrahydrofuran (THF), dimethylformamide (DMF), methanol, xylene, tetralin and acetone solvents as gasifications agent. The effect of the use of other solvents instead of water as the gasifying agent on the gasification performance was evaluated in terms of the total gas volume produced, the hydrogen gas content of the product gas and the distribution of other gases in the product gas. At operating temperature of $700^{\circ} \mathrm{C}$, the total gas volume and hydrogen gas production produced were greater than that of water for all solvents. Methanol was the solvent that provides the highest gasification efficiency at $700{ }^{\circ} \mathrm{C}$. At the operating temperature of $900{ }^{\circ} \mathrm{C}$, the highest gasification yields were obtained with THF, DMF and methanol solvents, respectively. The most effective gasifying agent at this temperature was THF with a total gas volume of $3650 \mathrm{~mL}$ and a volume of hydrogen gas of $2478 \mathrm{~mL}$.
\end{abstract}

Keywords: coal, biomass, co-gasification, hydrogen

DOI: $10.7176 / \mathrm{JSTR} / 5-7-05$

\section{Çan Linyitinin Sorgum Biyokütlesi ile Birlikte Gazlaştırılmasında Farklı Çözücülerin Etkisi}

\section{Özet}

$\mathrm{Bu}$ çalışmada \%25 sorgum içeren sorgum/Çan linyiti karışımı $700{ }^{\circ} \mathrm{C}$ ve $900{ }^{\circ} \mathrm{C}$ sıcaklıklarda, suyun yanı sıra tetrahidrofuran (THF), dimetilformamid (DMF), metanol, ksilen, tetralin ve aseton çözücüleri kullanılarak gazlaştırılmıştır. Çözücü kullanımının gazlaştırma performansına etkisi üretilen toplam gaz hacmi, üretilen gaz karışımındaki hidrojen gazı içeriği ve diğer gazların dağılımları açısından değerlendirilmiştir. $700{ }^{\circ} \mathrm{C}$ sicaklıkta, kullanılan tüm çözücüler için üretilen toplam gaz hacmi ve hidrojen gazı üretimi sudan daha fazladır. Bu sıcaklıkta en yüksek gazlaşma verimi sağlayan çözücü metanol olmuştur. $900^{\circ} \mathrm{C}$ de yapılan gazlaştırmada ise en yüksek gazlaşma verimleri sırasıyla THF, DMF ve metanol çözücüleri ile elde edilmiştir. Bu sıcaklıkta en etkin çözücü $3650 \mathrm{~mL}$ toplam gaz hacmi ve $2478 \mathrm{~mL}$ hidrojen gazı hacmi ile THF olmuştur.

Anahtar kelimeler: kömür, biyokütle, birlikte gazlaştırma, hidrojen.

\section{Giriş}

Dünya enerji ihtiyacının yaklaşık\% 29'u hala kömür tarafından karşılanmakta ve elektriğin ise \% 40'1 kömür kaynaklı teknolojilerden üretilmektedir (www.worldenergy.org). Çevre sorunlarına rağmen, mevcut kömür rezervleri, alternatif enerjilerin üretim maliyetleri, enerji kaynaklarının kullanım miktarları ve bu istatistiklerin geleceğe ekstrapolasyonları, kömürün geleceğin enerji kaynakları arasındaki yerini bir süre daha koruyacağını göstermektedir (www.iea.org). Kömür alanındaki son dönem araştırmalar, özellikle kömürün çevre üzerindeki olumsuz etkileri azaltmak için daha temiz yöntemler geliştirmeye odaklanmaktadır. Gazlaştırma, kömürün daha temiz bir şekilde işlenebileceği alternatif bir 
teknolojidir. Bu yöntemde kömür, buhar, hava ve / veya oksijen, karbon dioksit veya bu gazların bir karışımı ile $800^{\circ} \mathrm{C}^{\prime}$ nin üzerindeki reaksiyon sıcaklıklarında reaksiyona sokulur ve başlıca hidrojen gazı olmak üzere, karbon monoksit, karbon dioksit ve metan içeren bir sentez gazı karışımına dönüştürülür (Minchener, 2005). Kömürün buharlaştırılması yoluyla hidrojen üretimi, kömürün temiz kullanımı ve kömürün gelecekteki enerji teknolojilerine entegrasyonu için güçlü bir alternatiftir (Hirsch vd., 1982). Son yıllarda yapılan bazı çalışmalar, kömürün tek başına gazlaştırılması yerine biyokütle ile birlikte gazlaştırılmasının bazı avantajları olduğunu göstermiştir. Kömür çarının düşük oksidasyon kinetiği nedeniyle tamamlanamayan dönüşümü, kömür gazlaştırma sistemlerinde enerji verimliliğinde bir azalmaya neden olmaktadır. Bu nedenle, kömürün oksidasyon reaksiyonlarını hızlandırmak için çeşitli katalizörler kullanılır (Wood ve Sancier, 1984). Örneğin, alkali ve toprak alkali metal tuzları, geçiş metalleri ve bunların kompozitleri gibi farklı katalizörler, katalitik kömür gazlaştırma işlemlerinde kullanılmaktadır (Veraa ve Bell, 1978; Lin ve ark., 2017). Bu mineraller doğal olarak biyokütlenin inorganik bileşenlerinde bulunm ve bu minerallerin katalitik etkilerinden dolayı kömür ve biyokütle birlikte gazlaştırıldığında bazı sinerjik etkiler gözlenir. Literatürde kömür ve biyokütlenin birlikte gazlaştırılması ile ilgili birçok yayın vardır (Pan ve ark. 2000); Sjöstrom ve ark. 1999; Brown ve ark. 2000; Howaniec ve ark., 2011; Ren ve ark. , 2012; Howaniec ve Smolinski, 2013; Rizkiana ve diğerleri, 2014; Ellis ve diğerleri, 2015. Kömür ve biyokütlenin birlikte gazlaştırması ile hidrojen üretimi genellikle su buharı kullanılarak gerçekleştirilmektedir. Sorgum ve Çan linyitinin su buharı ile birlikte gazlaştırılmasına ait bulgular literatürde mevcuttur (Seçer ve ark., 2018). Gazlaştırma prosesinde su yerine kullanılan farklı çözücülerin biyokütle ve kömürün yapısında bulunan bileşenlerle etkileşime girerek gazlaştırmaya toplam gaz verimi açsından katkıda bulunabileceği düşünülmektedir. Gazlaştırma proseslerinde gaz ürünlerin yanı sıra yüksek miktarda katran oluşumu da gerçekleşmektedir ve katran oluşumu gazlaştırma proseslerinin en temel sorunlarından biridir. Katran çoğunlukla çoklu halkalı aromatik bileşiklerin oluşturduğu hidrokarbon kompleksi olarak tanımlanır (Anis ve ark. 2011). Pilot gazlaştırma sistemlerinde oluşan katran zamanla birikerek proses uygulanabilirliğinde sorunlara yol açmaktadır. Gazlaştırma sonrası katran oluşumunun azaltılması proseslerin sürdürülebilir uygulamaları açısından büyük önem taşımaktadır. organik çözücülerin kullanımının, organik çözücülerin kompleks organik yapıları çözebilme olasıllğından ötürü gazlaştırma sonrası oluşan katran miktarını azaltılabileceği öngörülmüştür. $\mathrm{Bu}$ nedenle bu çalışmada sorgum ve Çan linyiti su haricinde farklı çözücüler kullanılarak birlikte gazlaştırılmış ve bu çözücülerin üretilen toplam gaz hacmi, üretilen gaz içeriği ve gazlaştırma sonrası katran oluşumu üzerine etkileri incelenmiş̧ir.

\section{Materyal ve Metot}

\subsection{Materyal}

$\mathrm{Bu}$ çalışmada Çan linyiti ve sorgum biyokütlesi hammadde olarak kullanılmıştır. Çan linyiti ve sorgum ham biyokütlesinin kısa analiz sonuçları Tablo l'de verilmiştir. ; su, metanol, dimetilformamid (DMF), tetralin, N-Metil-2-Pirrolidon (NMP), tetrahidrofuran (THF), ksilen, hidrojen peroksit $\left(\mathrm{H}_{2} \mathrm{O}_{2}\right)$ ve aseton çözücüleri kullanılmıştır.

Table 1. Sorgum biyokütlesi ve Çan linyitinin kısa analiz değerleri.

\subsection{Metot}

\begin{tabular}{|c|c|c|}
\hline & Sorgum & Çan Linyiti \\
\hline $\mathrm{C}\left(\mathrm{ağ}^{\mathrm{a}} \%, \mathrm{kuru}\right)$ & 58.6 & 56.3 \\
\hline $\mathrm{N}$ (ağ \%, kuru) & 4.7 & 1.0 \\
\hline $\mathrm{H}$ (ağ \%, kuru) & 1.4 & 3.8 \\
\hline $\mathrm{S}$ (ağ \%, kuru) & - & 5.6 \\
\hline $\mathrm{O}(\mathrm{ağ} \%, \mathrm{kuru})^{\mathrm{b}}$ & 35.3 & 10.1 \\
\hline $\operatorname{Nem}($ ağ \%) & 0.1 & 6.1 \\
\hline Kül (wt \%, kuru) & - & 23.1 \\
\hline Uçucu bileşen (ağ \%, kuru) & $t e^{c}$ & 37.6 \\
\hline Sabit karbon (ağ \%, kuru) & te & 39.3 \\
\hline
\end{tabular}

${ }^{\mathrm{a}}$ :ağırlık; ${ }^{b}$ farktan hesaplandı; ${ }^{\mathrm{c}}$ te: tespit edilmedi

\subsubsection{Gazlaștırma deneyleri}

Tüm gazlaştırma deneyleri sabit yataklı bir reaktörde gerçekleştirilmiştir. \% 25 biyokütle içeren kömür/biyokütle karışımı, kuru-külsüz bazda (kkb) toplam miktar 1,0 g olacak şekilde karıştırılmış ve paslanmaz çelik reaktöre $(0,56$ inç iç çap, dış çap 1,4 ") yerleştirilmiştir. Reaktör yüksek sıcaklık firını içinde dakikada $30^{\circ} \mathrm{C}$ 'lik artışla istenilen sıcaklığa kadar ısıtılımıştır. Deneyler atmosferik basınçta 700 ${ }^{\circ} \mathrm{C}$ ve $900{ }^{\circ} \mathrm{C}$ olmak üzere iki farklı sıcaklıkta gerçekleştirilmiştir. Su ve diğer çözücüler sisteme $0,5 \mathrm{~mL}$

36 | P a g e 
$\mathrm{dk}^{-1}$ akış hızında bir HPLC pompası yardımı ile gönderilmiştir. Kolondan çıkan gaz ve sıvı karışımı bir geri soğutucu içerisinden geçirilmiş ve yoğunlaşan sıvı, gaz/sıvı ayırıcı bir rezervuarda gaz ürünlerden ayrılmıştır. Ayrılan gaz karışımı daha sonra bir kadmiyum asetat çözeltisinden geçirilerek açığa çıkan $\mathrm{H}_{2} \mathrm{~S}$ in $\mathrm{CdS}$ şeklinde çöktürülmesi sağlanmıştır. $\mathrm{H}_{2} \mathrm{~S}$ den ayrılan gaz karışımı bir gaz toplama büretinde toplanarak hacmi ölçülmüş ve daha sonra iki kanallı termal elektriksel iletkenlik detektörlü (TCD) Varian-450 gaz kromatografi cihazı ile kantitatif ve kalitatif olarak analiz edilmiştir. Gaz analizleri ile ilgili ayrıntılı bilgiye önceki çalışmalardan ulaşılabilir (Hesenov ve ark., 2011).Gazlaştırma düzeneğine ait şema Şekil 1'de verilmiştir.

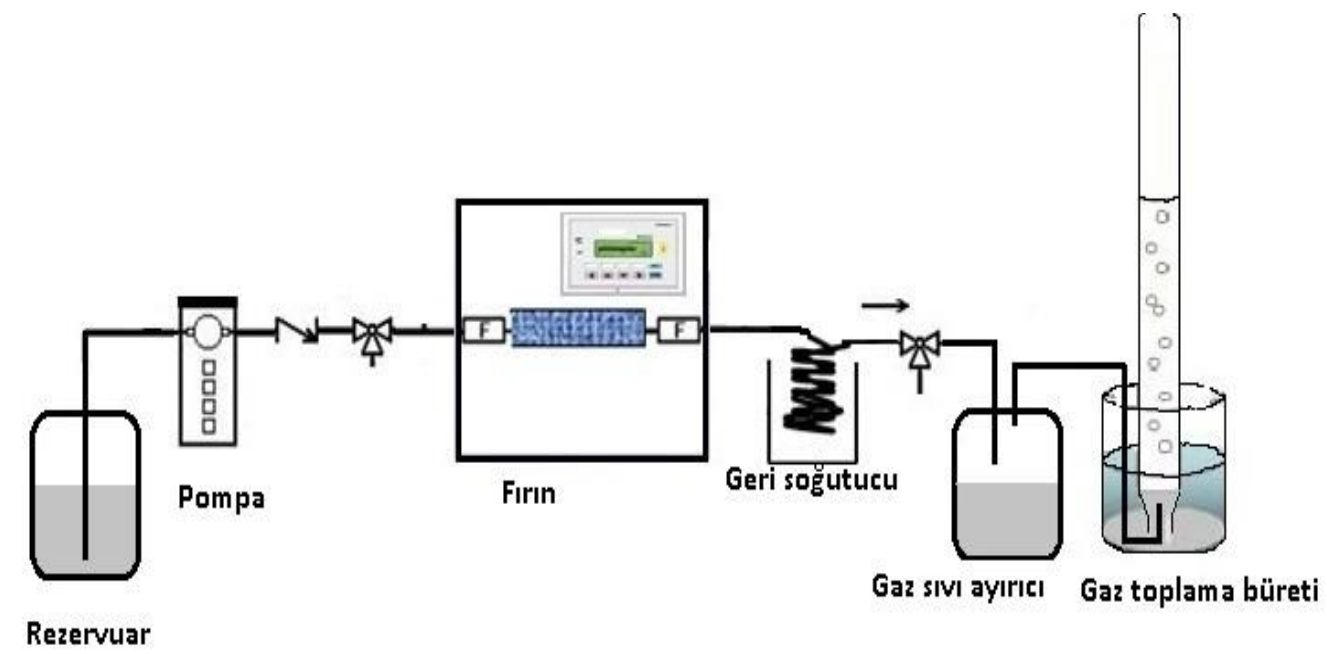

Şekil 1. Gazlaştırma sistemi

\section{Bulgular ve Tartışma}

$700{ }^{\circ} \mathrm{C}$ 'de yapılan çözücü eşliğindeki gazlaştırmalar sonucunda elde edilen gaz hacimleri Tablo 2'de verilmiştir. Tüm gazlaştırma işlemleri sonrasında oluşan gaz bileşiminde ortak olarak başlıca $\mathrm{H}_{2}$ olmak üzere $\mathrm{CO}, \mathrm{CO}_{2}$ ve $\mathrm{CH}_{4}$ gazları bulunmaktadır. Ayrıca THF ve DMF ile yapılan gazlaştırmalarda üretilen gaz karışımı içeriğinde oldukça düşük oranda (\%1-1,5) $\mathrm{C}_{2} \mathrm{H}_{2}$ bileşeni gözlemlenmiştir. Bu sıcaklıkta, hem toplam gaz hacmi $(2270 \mathrm{~mL})$ hem de gaz bileşimindeki $\mathrm{H}_{2}$ oranı açısından $(\% 71,2)$ en yüksek verim sağlayan gazlaştırıcı ajan metanol olmuştur. Çözücüler eşliğinde yapılan bütün gazlaştırmalarda elde edilen toplam gaz hacimleri, suyun kullanılması sonucu elde edilenden daha fazladır. Sonuç olarak çözücü kullanımının $700{ }^{\circ} \mathrm{C}$ de gazlaştırmaya toplam gaz hacmi açısından pozitif etki sağladığ söylenebilir.

Prosesin hidrojen seçiciliği her bir çözücü için eşitlik (1) kullanılarak hesaplanmış ve sonuçlar Şekil 2 de verilmiştir. Üretilen gaz karışımındaki hidrojen oranının en yüksek olduğu gazlaştırıcı ajan ksilendir $(\% 72,0)$. En yüksek toplam gaz veriminin sağlandığı gazlaştırıcı ajan metanol ile elde edilen gaz karışımındaki hidrojen oranı ise \% 71,2 ile ikinci sıradadır. $700{ }^{\circ} \mathrm{C}$ de her iki çözücünün de hidrojen seçiciliğinin sudan fazla olduğu görülmektedir. Ancak elde edilen ürün gazlarının toplam hacimleri değerlendirildiğinde, ksilenin kullanıldığı gazlaştırmada toplam gaz miktarının düşük olması, gaz karışımındaki \% oranı yüksek de olsa, üretilen hidrojen gazı hacminin düşük olmasına neden olmuştur. $\mathrm{Bu}$ nedenle hidrojen üretim verimi açısından en etkin çözücü metanoldür. Hidrojen seçiciliği en düşük olan gazlaştırıcı ajan \% 63,0 $\mathrm{H}_{2}$ oranı ile asetondur. Ürün gazlarının hidrojen gazı içerikleri hacimsel olarak değerlendirildiğinde, çözücü kullanımının $700{ }^{\circ} \mathrm{C}$ gazlaştırma sıcaklığında hidrojen verimine de pozitif etki sağladığ1 söylenebilir. Gazlaştırma işlemleri sonrasında reaktör sisteminde kalan katran miktarları Tablo 2 de verilmiştir. Sonuçlar su yerine çözücü kullanılmasının gazlaştırma işlemleri sonrasında oluşan katran miktarını azalttığını göstermektedir.

$$
\text { Hidrojen seçiciliğ } i=\operatorname{mol~H} 2 /(\operatorname{mol}[(H 2+C O 2+C O+C H 4)] \times 100
$$


Tablo 2. $700{ }^{\circ} \mathrm{C}$ de, gazlaştırıcı olarak farklı çözücülerin kullanıldığı deneylerden elde edilen gazların toplam hacimleri ve $\%$ bileşimleri ve deneyler sonrasında reaktör sisteminde oluşan katran miktarları.

\begin{tabular}{|c|c|c|c|c|c|c|c|}
\hline \multirow{2}{*}{ 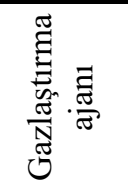 } & \multirow{2}{*}{$\begin{array}{l}\text { Toplam } \\
\text { Gaz } \\
\text { Hacmi } \\
\text { (mL) }\end{array}$} & \multicolumn{4}{|c|}{ Oluşan gazlar (mL) } & \multirow[b]{2}{*}{$\mathrm{C}_{2} \mathrm{H}_{2}$} & \multirow{2}{*}{ Katran $(\mathrm{g})$} \\
\hline & & $\mathrm{H}_{2}$ & $\mathrm{CO}$ & $\mathrm{CH}_{4}$ & $\mathrm{CO}_{2}$ & & \\
\hline Metanol & $2270 \pm 33$ & $1616 \pm 12$ & $300 \pm 10$ & $127 \pm 6$ & $224 \pm 11$ & - & $0,032 \pm 0,002$ \\
\hline DMF & $2070 \pm 20$ & $1397 \pm 21$ & $304 \pm 8$ & $140 \pm 5$ & $217 \pm 9$ & $6,0 \pm 0,1$ & $0,030 \pm 0,002$ \\
\hline Tatralin & $1950 \pm 26$ & $1337 \pm 23$ & $239 \pm 6$ & $74 \pm 6$ & $300 \pm 8$ & - & $0,028 \pm 0,001$ \\
\hline NMP & $1940 \pm 24$ & $1301 \pm 11$ & $217 \pm 8$ & $54 \pm 9$ & $360 \pm 12$ & - & $0,010 \pm 0,001$ \\
\hline $\mathrm{THF}$ & $1840 \pm 57$ & $1232 \pm 14$ & $246 \pm 9$ & $46 \pm 4$ & $296 \pm 10$ & $22,0 \pm 0,1$ & $0,031 \pm 0,001$ \\
\hline Ksilen & $1625 \pm 36$ & $1170 \pm 16$ & $164 \pm 8$ & $74 \pm 3$ & $214 \pm 9$ & - & $0,022 \pm 0,001$ \\
\hline $\mathrm{H}_{2} \mathrm{O}_{2}$ & $1609,7 \pm 56$ & $1060 \pm 20$ & $196 \pm 7$ & $62 \pm 6$ & $292 \pm 9$ & - & $0,034 \pm 0,001$ \\
\hline Aseton & $1600 \pm 36$ & $1008 \pm 23$ & $211 \pm 6$ & $89 \pm 8$ & $158 \pm 3$ & - & $0,041 \pm 0,001$ \\
\hline $\mathrm{Su}$ & $1331 \pm 12$ & $929 \pm 8$ & $155 \pm 3$ & $55 \pm 7$ & $189 \pm 6$ & - & $0,044 \pm 0,004$ \\
\hline
\end{tabular}

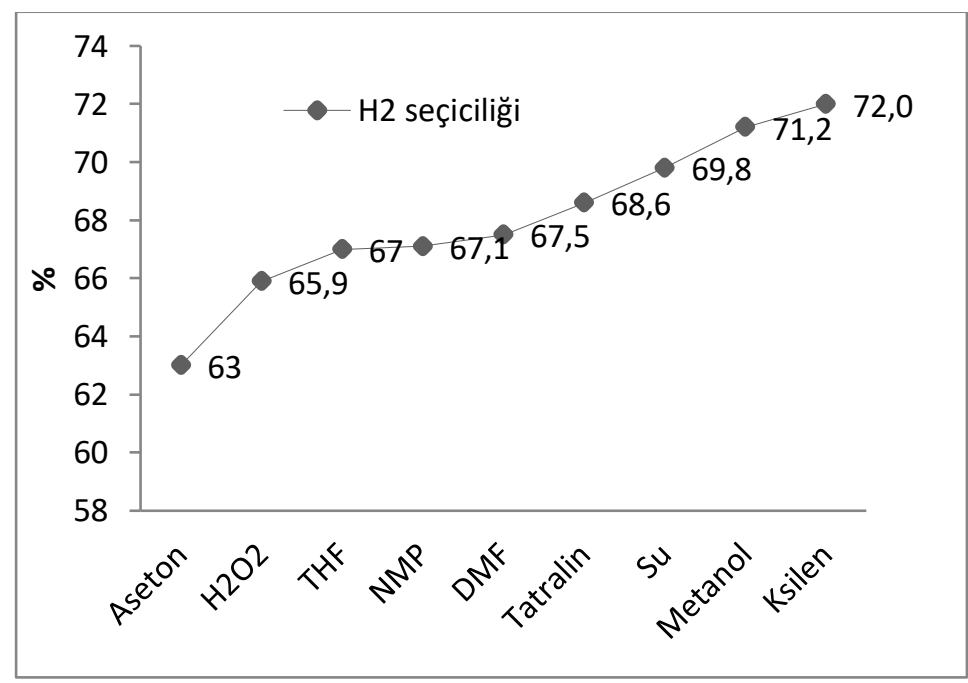

Şekil 2. $700^{\circ} \mathrm{C}$ sıcaklıkta farklı çözücüler eşliğinde yapılan gazlaştırmalarda elde edilen ürün gazlarının $\% \mathrm{H}_{2}(\mathrm{~mol} / \mathrm{mol})$ oranları.

$900{ }^{\circ} \mathrm{C}$ de, çözücü eşliğinde yapılan tüm deneylerde, gaz bileşimlerinde ortak olarak $\mathrm{H}_{2}, \mathrm{CO}, \mathrm{CO}_{2}$ ve $\mathrm{CH}_{4}$ bulunmaktadır. Ayrıca THF ve DMF ile yapılan gazlaştırmalarda üretilen gaz karışımı içeriğinde \%1-1,5 oranlarında $\mathrm{C}_{2} \mathrm{H}_{2}$ bileşeni gözlemlenmiştir. Şekil 3, çeşitli çözücüler eşliğinde yapılan gazlaştırma deneylerinden elde edilen toplam gaz hacimlerini göstermektedir. En yüksek toplam gaz hacmi THF çözücüsü kullanılarak yapılan gazlaştırmadan elde edilmiştir. Ayrıca, metanol ve DMF çözücülerinin kullanıldığı deneylerde de, standart gazlaştırıcı ajan su ile yapılan gazlaştırmada edilenden daha fazla gaz elde edildiği görülmektedir. Bu durum çözücülerin bu sıcaklıkta kendilerinin de parçalanıp gaz ürünlere dönüşmesinden kaynaklı olmakla birlikte gaz fazındaki çözücü moleküllerinin kömür ve biyokütlenin karmaşık yapısına nüfuz ederek çözünmesine neden olmasından kaynaklı da olabilir. Ksilen, aseton, hidrojen peroksit, NMP ve tetralin kullanıldığında ise standart su buharı gazlaştırmasında elde edilenden daha az gaz ürün oluştuğu gözlemlenmiştir. Şekil 4'te çözücülerle yapılan gazlaştırmalar sonucu oluşan hidrojen gazının üretilen gaz karışımındaki oranları hidrojen seçiciliği açısından değerlendirilmiştir. Bu sıcaklıkta gazlaşan toplam ürün miktarı metanol, DMF ve THF kullanımı sonucu artmasına karşın, üretilen gaz karışımındaki hidrojen miktarının en yüksek oranı su kullanıldı̆̆ında elde 
edilmektedir. Ancak, çözücülerin toplam gaz hacimlerini arttırmış olmaları, her ne kadar karışımdaki hidrojenin \% oranlarını düşürüyor olsalar da, hacimsel olarak üretilen hidrojenin miktarlarının artmasına neden olmuştur. Ancak diğer çözücülerle yapılan gazlaştırmalarda elde edilen ürün gazlarının hidrojen içerikleri hem oransal hem de hacimsel olarak su ile elde edilenden daha azdır. Dolayısı ile $900{ }^{\circ} \mathrm{C}$ yapılacak olan bir gazlaştırma işleminden elde edilen hidrojen gazının miktarı su yerine THF, DMF ve metanol kullanılarak arttırılabilir. Çözücü kullanımının gaz karışımındaki $\mathrm{CO}_{2}, \mathrm{CO}$ ve $\mathrm{CH}_{4}$ gazlarının dağılımına etkisi Şekil 5'te gösterilmektedir. Bütün deneyler için, gazlaştırmadan elde edilen gaz karışımında hidrojenden sonra en fazla orana sahip olan gazın $\mathrm{CO}_{2}$ olduğu görülmektedir. Üretilen gazdaki $\mathrm{CO}_{2}$ 'nin en fazla olduğu gazlaştırma $\mathrm{H}_{2} \mathrm{O}_{2}$ eşliğinde yapılmıştır. $\mathrm{Bu}$ çözücünün kullanımının aynı zamanda karışımın karbon monoksit miktarını da azalttığı gözlemlenmektedir. Hidrojen peroksit, hidrojen seçiciliği açısından en iyi üçüncü çözücüdür. Ancak hidrojen peroksit kullanımı toplam gaz hacmi açsından suya nazaran negatif bir etki yaratmıştır ve bu durumda bu çözücünün gazlaştırmada hidrojen üretimini arttırması söz konusu değildir. Hidrojen peroksitin yüksek sıcaklıklarda parçalanması sonucu açığa çıkan oksijen, gazlaştırmada hava/oksijen/ su buharı dengesindeki oksijen oranını yükselterek gazlaştırıcı ajan konsantrasyonun azalmasına neden olmuştur. Reaksiyon ortamında oksijen gazının aşırısı ayrıca eksik yanma reaksiyonları yerine tam yanma reaksiyonlarının daha fazla gerçekleşmesine neden olmuş olabilir. $\mathrm{Bu}$ da, $\mathrm{CO}$ oluşumunun azalması ile birlikte oluşan $\mathrm{CO}_{2}$ miktarının artmasına neden olur. Hidrojen seçiciliği yüksek olan bir diğer çözücü ksilen için de benzer bir durum söz konusudur. Bu çözücü varlığında yapılan gazlaştırmadan elde edilen gaz hacmi nispeten düşüktür ve bu durumda bu çözücü ile yapılan gazlaştırmada elde edilen hidrojen gazı miktarı da hacimsel olarak düşük olacaktır. Tetralin çözücüsü ile elde edilen gaz karışımının hidrojen oranı \% 69,3 ile dördüncü sıradadır ancak tetralin çözücüsü eşliğinde yapılan gazlaştırma sonucu elde edilen toplam gaz hacmi oldukça düşük olduğundan bu çözücü ile elde edilen hidrojen gazı hacminin en düşük değerde olduğu gözlemlenmiştir. Farklı çözücülerin kullanıldığ sisteminde kalan katran miktarları Şekil 6'da karşılaştırılmaktadır. Sonuçlar su ile yapılan standart gazlaştırma ile kıyaslandığında, çözücü kullanımının katran oluşumunu azalttığını göstermektedir. En az katranın, tetralin gazlaştırıcı ajanı varlığında yapılan gazlaştırmada oluştuğunu göstermektedir. Tetralinin $900{ }^{\circ} \mathrm{C}$ deki gazlaştırma performansı da diğer çözücülere nazaran düşüktür ve katran oluşumundaki bu azalmanın gazlaşan ürün miktarının azalmış olmasından kaynaklandığ düşünülmektedir. Katran miktarının en az olduğu ikinci çözücünün metanol olduğu görülmektedir. 900 ${ }^{\circ} \mathrm{C}$ de hem toplam gaz verimi hem de hidrojen verimi açısından en iyi performansı gösteren iki çözücü olan THF ve DMF eşliğinde yapılan gazlaştırmalar sonucunda katran oluşumunun da sıya göre yaklaşık \% 50 daha az olduğu görülmektedir. Bu sonuçlara dayanarak, çözücülerin kömür ve biyokütlenin yapılarına yer alan farklı fonksiyonel grupları ile etkileşime girebildiği ve özellikle katran içinde yer alan büyük molekül ağırlıklı hidrokarbonların ve aromatik yapıların oluşmasını engellediği söylenebilir.

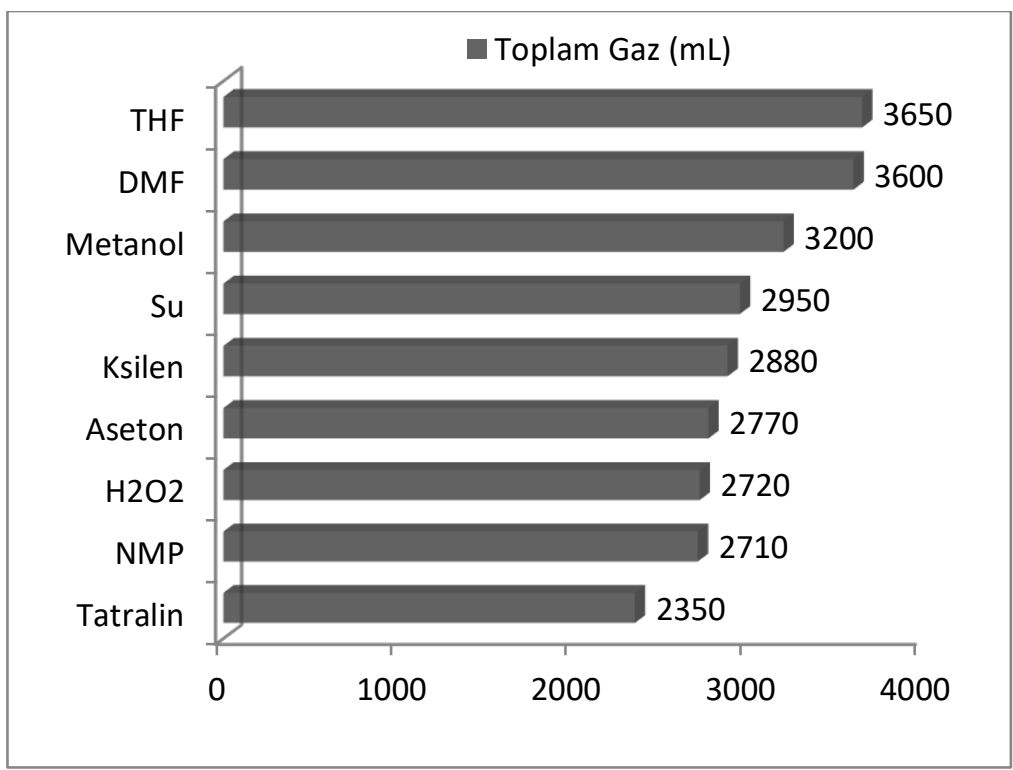

Şekil 3. $900{ }^{\circ} \mathrm{C}$ sıcaklıkta farklı çözücüler eşliğinde yapılan gazlaştırmalarda elde edilen toplam gaz hacimleri. 

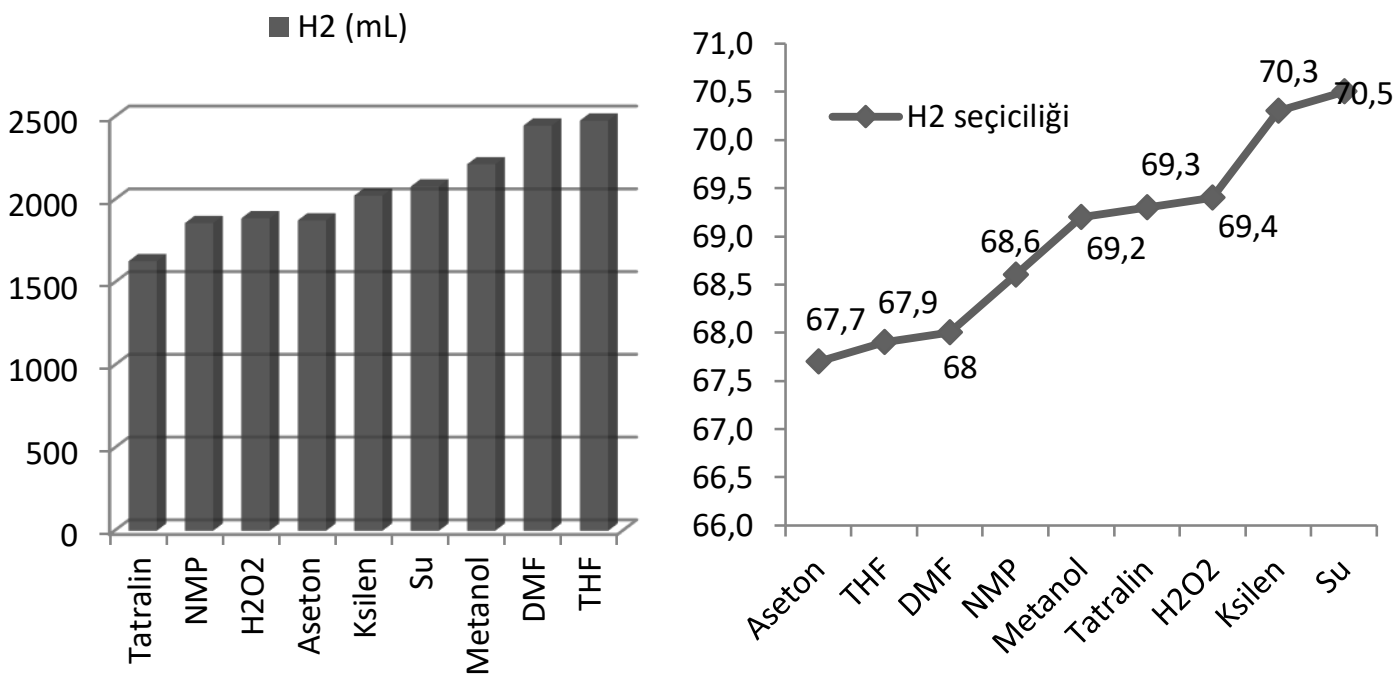

Şekil 4. $900{ }^{\circ} \mathrm{C}$ sıcaklıkta farklı çözücüler eşliğinde yapılan gazlaştırmalarda elde edilen hidrojen gazlarının a) hacimleri b) karışımdaki \% mol oranları.

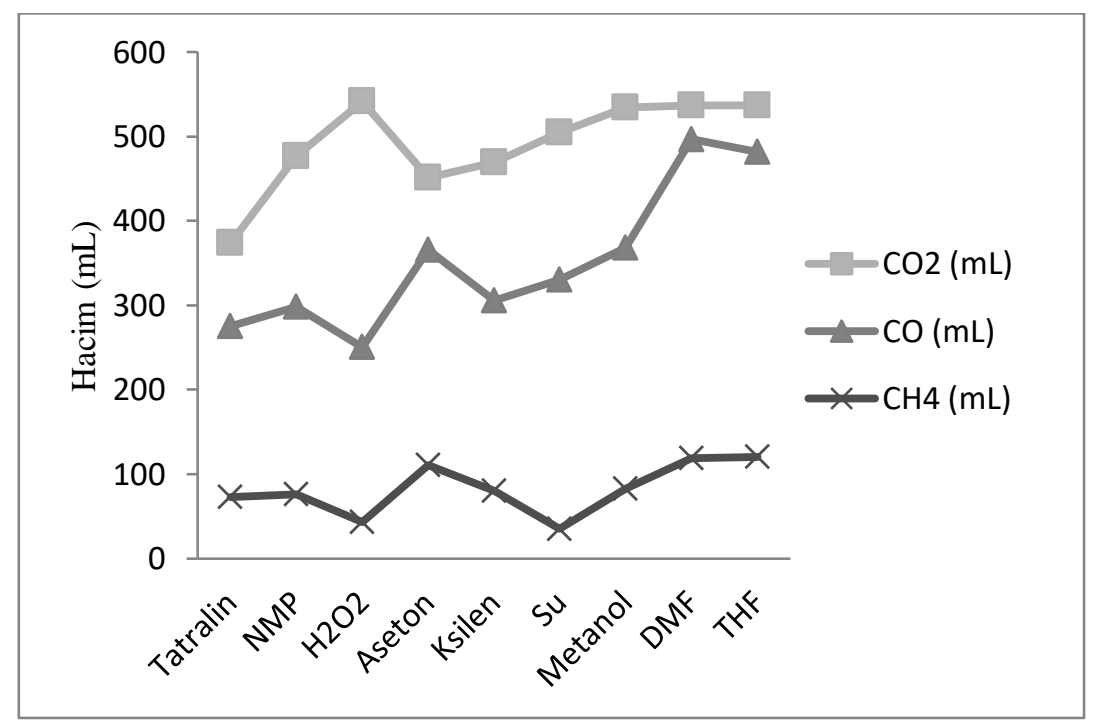

Şekil 5. $900{ }^{\circ} \mathrm{C}$ sıcaklıkta farklı çözücüler eşliğinde yapılan gazlaştırmalarda elde edilen hidrojen gazı haricindeki gazların dağılımları. 


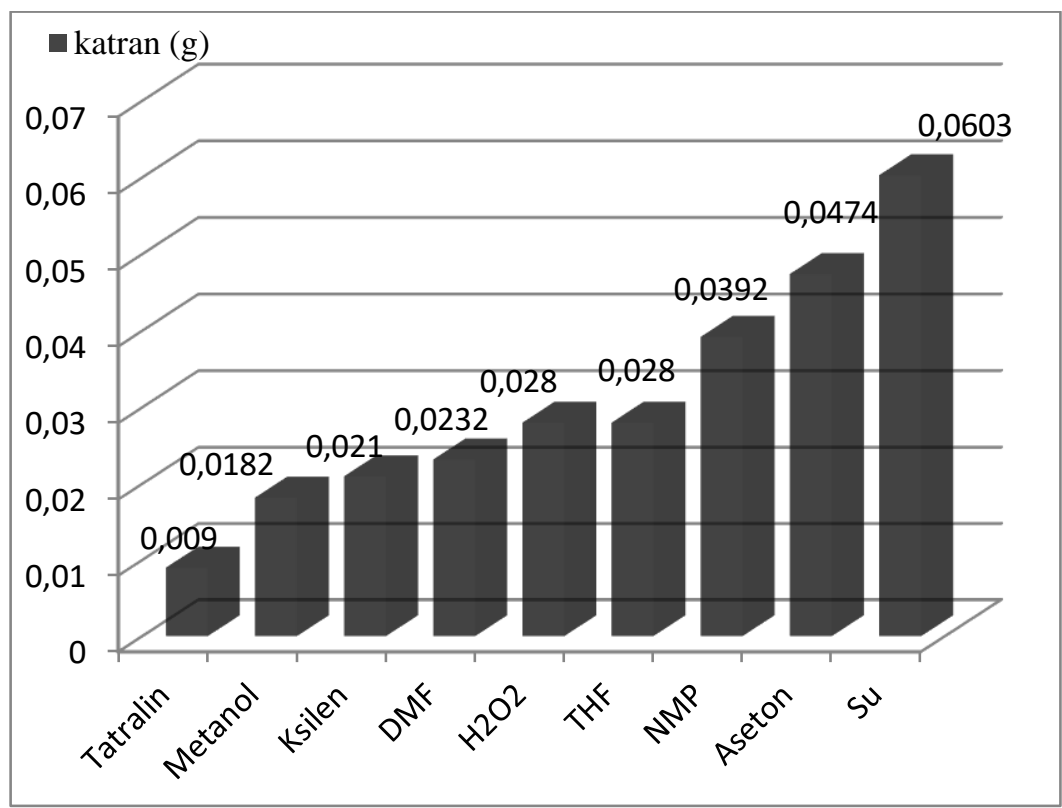

Şekil 6. $900{ }^{\circ} \mathrm{C}$ sıcaklıkta, farklı çözücüler eşliğinde yapılan gazlaştırmalar sonrasında reaktör sisteminde kalan katran miktarlar1.

\section{Sonuç}

$\mathrm{Bu}$ çalışmada sorgum biyokütlesi ve Çan linyitinin birlikte gazlaştırılmasında $700{ }^{\circ} \mathrm{C}$ ve $900{ }^{\circ} \mathrm{C}$ sıcaklıklarda, farklı çözücüler kullanılmış ve bu çözücülerin gazlaştırma verimine etkileri toplam gaz ve hidrojen gazı üretimi açısından değerlendirilmiştir. $700{ }^{\circ} \mathrm{C}$ de yapılan gazlaştırmalarda en yüksek gazlaştırma ve hidrojen verimi sağlayan çözücü metanoldür. Çözücü kullanımı, bu sıcaklıkta yapılan gazlaştırma deneylerinde, tüm çözücüler için gazlaştırma ve hidrojen gazı verimi açısından suya nazaran daha pozitif bir etki sağlamıştır. $700{ }^{\circ} \mathrm{C}$ geleneksel gazlaştırma prosesi için nispeten 1lımlı bir sıcaklıktır ve genellikle gazlaşma verimi düşüktür. Bu sıcaklıkta su yerine çözücü kullanımının prosesin gazlaştırma verimini arttırdığ 1 gözlemlenmiştir.

$900{ }^{\circ} \mathrm{C}$ sıcaklıkta en iyi gazlaştırma performansı gösteren üç çözücü sırasıyla THF, DMF ve metanol olmuştur. Üretilen gaz içeriğindeki $\mathrm{H}_{2}$ 'nin \% oranının en yüksek olduğu gazlaştırıcı ajan \% 70,5 (mol/mol) $\mathrm{H}_{2}$ oranı ile sudur. Ancak THF (3650 mL), DMF (3600) ve metanolün (3200 mL) kullanıldığ 1 deneylerde üretilen gaz karışımı hacimleri suyun kullanıldığı gazlaştırmadan elde edilenden daha fazladır (2950 mL). Bu durumda, karışımdaki $\mathrm{H}_{2}$ oranları nispeten düşük olsa da, $900{ }^{\circ} \mathrm{C}$ de bu çözücülerle yapılan gazlaştırmalar sonucu elde edilen $\mathrm{H}_{2}$ gazı miktarının daha fazla olmaktadır. $\mathrm{Bu}$ çözücülerin kullanıldığı deneyler sonucu oluşan katran miktarları da su kullanılarak yapılan gazlaştırmada oluşan katran miktarından yaklaşık \%50 daha azdır. Dolayısı ile $900{ }^{\circ} \mathrm{C}$ sıcaklıkta su yerine THF, DMF ve metanol çözücülerinin kullanımı, gazlaştırma prosesini hem toplam gaz hacmi ve hidrojen üretimi açsından daha verimli hale getirecek, hem de katran oluşumunu azaltarak gazlaştırma sistemini daha uzun süre kullanılabilir hale getirebilecektir.

\section{Referanslar}

Anis, S., Zainal, Z. (2011). Tar Reduction in Biomass Producer Gas via Mechanical, Catalytic and Thermal Methods: A Review. Renewable and Sustainable Energy Reviews, 15(5), 2355-2377.

Brown, C.R., Liu, K., Norton, G. (2000). Catalytic Effects Observed During The Co-Gasification of Coal and Switchgrass. Biomass Bioenergy, 18 (6), 499-506.

Ellis, N., Masnadi, S.M., Roberts, D.G., Kochanek, M.A., Ilyushechkin, A.Y. (2015). Mineral Matter İnteractions During Co-Pyrolysis of Coal and Biomass and Their Impact on Instrinsic Char CoGasification Reactivity. Chemical Engineering Journal, 279, 402-8.

Howaniec, N., Smolinski, A., Stanczyk, K., Pichlak, M. (2011). Steam Co-Gasification of Coal and Biomass Derived Chars with Synergy Effects as an Innovative Way of Hydrogen-Rich Gas Production. Int J Hydrogen Energy ,36(22), 14455-63. 
Howaniec, N., Smolinski, A. (2013). Steam Co-Gasification of Coal and Biomass- Synergy in Reactivity of Fuel Blends Char. Int J Hydrogen energy, 38(36), 16152-60.

Liu, X., Tu, Y., Xu, X.,Liu, Z. (2017).The Development and Research Prospect on Catalytic Coal. Gasification. Chemical Engineering Transactions, 61, 1165-1170.

Pan, Y.G., Velo, E., Roca, X., Manya, J.J., Puigjaner, L. (2000). Fluidized-Bed Co-Gasification of Residual Biomass/Poor Coal Blends for Fuel Gas Production. Fuel, 79(11), 1317-26.

Ren, H.J., Zhang, Y.Q., Fang, Y.T., Wang, Y. (2012). Co-Gasification Properties of Coal Char and Biomass Char. Journal of Fuel Chemistry and technol, 40 (2) ,143-8.

Rizkiana, J., Guan, G., Widayatno, W.B., Hao, X., Huang, W., Tsutsumi, A., Abudula, A. (2014). Effect Of Biomass Type On The Performance of Co-gasification of Low Rank Coal with Biomass at Relatively Low Temperatures. Fuel, 134, 414-9.

Seçer, A., Küçet, N., Fakı, E., Hasanoğlu, A. (2018). Comparison of Co-Gasification Efficiencies of Coal, Lignocellulosic Biomass and Biomass Hydrolysate for High Yield Hydrogen Production. International Journal of Hydrogen Energy, 43( 46), 21269-21278.

Sjöstroöm, K., Chen, G., Yu, Q., Brage, C., Rosen, C. (1999).Promoted Reactivity of Char in CoGasification of Biomass and Coal: Synergies in the Thermochemical Process. Fuel, 78 (10), 118994.

Veraa, M.J., Bell, A.T. (1978). Effect of alkali metal catalysts on gasifications of coal char. Fuel, 57(4), 194-200.

Wood, B.J., Sancier, KM. (1984). The Mechanism of the Catayltic Gasification of Coal Char : A Critical Review. Journal of Catalysis reviews, 26(2), 233-279. 